\title{
ANALYSIS OF ABRASIVE WEAR OF DIAMOND SEGMENTS FOR GRINDING GRANITE SURFACES
}

\author{
Paweł RAJCZYK, Marcin KNAPIŃSKI \\ Czestochowa University of Technology, Częstochowa, Poland, EU \\ rajczyk.pawel@wip.pcz.pl, marcin.knapinski@wip.pcz.pl
}

https://doi.org/10.37904/metal.2019.966

\begin{abstract}
The results of research on diamond segments made on metallic binders and on synthetic - resin binders for granite surface grinding are presented. The results of investigations of hardness of abrasive segments were determined by the Brinell method for metallic and Shore segments (D) for segments on synthetic binders. The hardness of the segments affects the ability to hold the diamond grain in the binder, which is related to the wear of the abrasive segments during their work. Tribological tests of their wear during operation (in given research cycles) for which the weight losses of abrasive segments in the process of grinding the granite surface with hardness of 7 Mohs, with constant kinematic parameters and constant pressure were determined. The results of microscopic analysis of working surfaces of the tested segments were presented in order to determine the ability to hold diamond grain in a segment matrix, using a Nikon Eclipse MA200 microscope.
\end{abstract}

Keywords: Diamond abrasive segments, hardness tests, tribological tests, abrasive wear

\section{INTRODUCTION}

Research on abrasive diamond segments of discs intended for grinding the surface of stone materials made on metallic bond compositions, show a variable efficiency of the abrasive action depending on the abrasiveness of the adhesive matrix, which depends on the geometry and their hardness [1-8]. The results of the tests carried out on the hardness of the abrasive segments using the Brinell method showed at the same time a variable ability to hold the diamond grain in the binder, which translates into abrasive wear of the segments during their operation. The tests were carried out at constant kinematic parameters and constant pressure. Images from the presented microscopic analysis showed good ability to hold the diamond grains in the binder. The comparison of the efficiency of the abrasive segments for the treatment of stone surfaces was made by the method of assessing the mass loss of the segment and the percentage consumption of the diamond grain volume after each interaction cycle of $L=1065 \mathrm{~m}$.

For comparison, diamond segments formed on a polyurethane adhesive were examined on the basis [9-11]. Segments formed on such binders are characterized by the possibility of adjusting the hardness, which distinguishes the segments: soft, medium hardness and hard. Due to technological properties, the aim is to produce discs with high elasticity, which results from the disc working conditions and requires specification of their hardness in the range from medium to high. In order to ensure the shaping of the hardness of the disk, the conditions and material recommendations included in the literature sources were considered [12-18].

\section{TRIBOLOGICAL STUDIES OF DIAMOND DIAMONDS ON METALLIC FILLES}

The abrasive wear of diamond grains in the material of a metallic binder for two compositions of metallic compositions of diamond segment matrices was determined. The tests were performed on segments with metallic binders with a constant concentration of abrasive $K=30 \%(K$ - is the diamond concentration referred to 4 carats of diamond powder weight contained in $1 \mathrm{~cm}^{3}$ of binder segment volume, which is taken as $100 \%$ ) - synthetic MBD diamond powder with a grain size of 40/45 \# with the hardness of the metal bond A1 - 86.33 $\mathrm{HB}$ and $\mathrm{A} 2-101 \mathrm{HB}$. 
Due to the complex structure of the diamond segment, it is advisable to use an equivalent hardness of the material, which is a mixture of various materials including abrasive additive with a higher hardness than the binder. The equivalent hardness of a diamond segment is equal to the sum of the products of the percentage content of individual components and their hardness, as described in sources $[3,19]$.

The tested segments were subjected to the abrasion process on a $100 \mathrm{~mm}$ diameter disc at a speed of $\mathrm{n}=660 \mathrm{rpm}$ at a constant pressure load with a force of $20 \mathrm{~N}$, where the surface of the tested sample was $400 \mathrm{~mm}^{2}$. The grain condition was controlled after each abrasive cycle. The cycle of mutual abrasion of the sample with the treated material was $L=1065 \mathrm{~m}$.

Two groups of segments measuring $10 \times 40 \times 10 \mathrm{~mm}$ were subjected to abrasive action. The weight of the tested segments before the test cycle was: A1-SM1 $26.72985 \mathrm{~g}$, A2-T1 $36.0999 \mathrm{~g}$. The amount of exposed diamond grains before the first test cycle on the working surface for segments was: A1-SM1 $=126$ grains, for A2-T1 = 119 grains. The difference in the weight of the segments results from the used recipe of a metallic binder used to produce segments, which at the moment are subject to research by the "Poldiam" company for the purpose of developing an inventive project. The abrasive wear of the diamond segment binder was determined according to the weight method. The results of the measurements are summarized in Table 1, where the weight loss of segments after each test cycle is presented.

Table 1 Mass loss of diamond segments after each abrasive interaction cycle (RAD WAG WPA 40/160/C/1 weight with an accuracy of $0.00001 \mathrm{~g}$ )

\begin{tabular}{|c|c|c|c|c|c|c|c|}
\hline \multicolumn{7}{|c|}{ Weight loss as a result of tribological tests (g) } \\
\hline $\begin{array}{c}\text { Sample } \\
\text { no. }\end{array}$ & $\begin{array}{c}\text { Weight } \\
\text { before test }\end{array}$ & $\begin{array}{c}\text { Segment } \\
\text { weight loss } \\
\text { after 1 cycle }\end{array}$ & $\begin{array}{c}\text { Segment } \\
\text { weight loss } \\
\text { after the 2nd } \\
\text { cycle }\end{array}$ & $\begin{array}{c}\text { Segment } \\
\text { weight loss } \\
\text { after the 3rd } \\
\text { cycle }\end{array}$ & $\begin{array}{c}\text { Segment } \\
\text { weight loss } \\
\text { after the 4th } \\
\text { cycle }\end{array}$ & $\begin{array}{c}\text { Segment } \\
\text { weight loss } \\
\text { after the 5th } \\
\text { cycle }\end{array}$ & $\begin{array}{c}\text { Segment } \\
\text { weight loss } \\
\text { after the 6th } \\
\text { cycle }\end{array}$ \\
\hline A1-M1 & 26.72985 & 0.06903 & 0.06637 & 0.06610 & 0.06610 & 0.06563 & 0.06499 \\
\hline A2-T1 & 36.09199 & 0.09457 & 0.08763 & 0.08753 & 0.08699 & 0.08653 & 0.08190 \\
\hline
\end{tabular}

\section{TRIBOLOGICAL STUDIES OF DIAMOND SEGMENTS FORM FOR SYNTHETIC POLYURETHANE RESIN}

Abrasion tests were also carried out on diamond segments formed on a binder of polyurethane resin with the filler in the form of quartz powder. As abrasive, a synthetic MBD powder with a grain size of 40/45 \# and a concentration of $25 \%$ was used.

The samples were subjected to a kinematic interaction at $n=660 \mathrm{rpm}$ at the pressure of the segment with a force of $40 \mathrm{~N}$ during 6 test cycles of $60 \mathrm{~s}$, for which the weight loss of the matrix was determined (Table 2). The consumption of diamond grains was evaluated on the basis of the image of the working surface after each cycle with the estimation of the loss in volume of the used grains. Segments with polyurethane resins have demonstrated their satisfactory working efficiency. The segments were subjected to abrasive action in a pair with the surface of a granite plate with a hardness of 7 Mosh, which corresponds to the hardness according to Shore $97 \mathrm{ShD}$. The results of hardness testing of synthetic segments for the tested series of segments amounted to $60 \mathrm{ShD}$.

The performed tribological tests determining the weight loss of the segment matrix on a synthetic binder made of polyurethane resin modified with quartz powder are summarized in Table 2. 
Table 2 Mass loss of diamond segments after each abrasive interaction cycle (RAD WAG WPA 40/160/C/1 weight with an accuracy of $0.00001 \mathrm{~g}$ )

\begin{tabular}{|c|c|c|c|c|c|c|c|}
\hline \multicolumn{7}{|c|}{ Weight loss as a result of tribological tests (g) } \\
\hline $\begin{array}{c}\text { Sample } \\
\text { no. }\end{array}$ & $\begin{array}{c}\text { Weight } \\
\text { before } \\
\text { test }\end{array}$ & $\begin{array}{c}\text { Segment } \\
\text { weight loss } \\
\text { after 1 cycle }\end{array}$ & $\begin{array}{c}\text { Segment } \\
\text { weight loss after } \\
\text { the 2nd cycle }\end{array}$ & $\begin{array}{c}\text { Segment } \\
\text { weight loss } \\
\text { after the 3rd } \\
\text { cycle }\end{array}$ & $\begin{array}{c}\text { Segment } \\
\text { weight loss } \\
\text { after the 4th } \\
\text { cycle }\end{array}$ & $\begin{array}{c}\text { Segment } \\
\text { weight loss } \\
\text { after the 5th } \\
\text { cycle }\end{array}$ & $\begin{array}{c}\text { Segment } \\
\text { weight loss } \\
\text { after the 6th } \\
\text { cycle }\end{array}$ \\
\hline S1 & 2.46031 & 0.00371 & 0.00092 & 0.00058 & 0.00035 & 0.00022 & 0.00021 \\
\hline S2 & 2.31759 & 0.00476 & 0.00325 & 0.00165 & 0.00115 & 0.00093 & 0.00099 \\
\hline
\end{tabular}

The abrasion test related to the mass loss of the diamond segment die was conducted to assess the determination of the ability to hold the diamond grain in the diamond segment die. The assessment of the diamond grain holding capacity was carried out on the basis of the image taken under the microscope after each test cycle based on which the percentage loss of diamond grain volume was estimated, which is expressed as a percentage share of the volume loss determined for the grain surface distributed on the examined surface after each test cycle.

\section{ASSESSMENT OF DIAMETER GRAIN HOLDING LEVEL IN CONSUMPTION}

Intensity of abrasive wear of diamond grains with a hardness of $\mathrm{A} 1=86.33 \mathrm{HB}$ and $\mathrm{A} 2=101 \mathrm{HB}$, with a constant concentration of diamond in the binder which is $30 \%$, for $\mathrm{A} 1$ and $\mathrm{A} 2$, depends on the degree of hardness of the segment binder. The wear value was determined for 5 abrasive cycles depending on the abrasive influence path, which was illustrated in Figure 1, where the abrasive wear $(h)$ of diamond grains for segments on a metallic bond (A1, A2) and on a synthetic bond (S1) is shown.

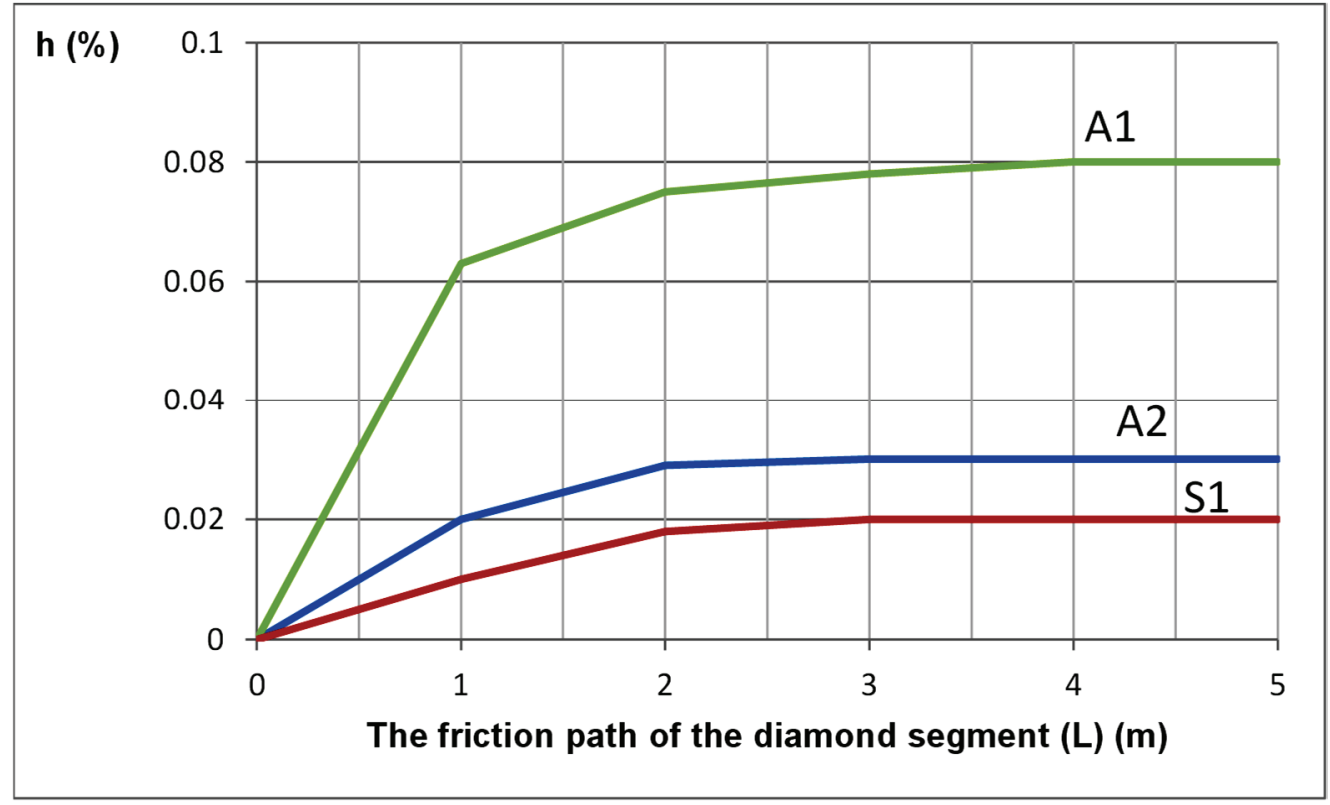

Figure 1 Dependence of consumption of abrasive grain $(h)$ with grain size 40/45 \# in metal segments with hardness A1-86.33 HB and A2-101 HB and in segment formed from polyurethane resin S1 - $60 \mathrm{ShD}$, for five cycles of abrasive action $(L)$, where $h$ - loss of diamond grains in $\%$ related to the total volume of grains present on the control surface before each test cycle 
The evaluation of the optical analysis showed a variable degree of diamond grain wear depends on the type and hardness of the binder. The development of the destruction of diamond grains in both types of segments is slightly diversified. In the A1 segment there is a higher consumption, which is shown generally in the graph Figure 1. After the transition period of the abrasive road of $2000 \mathrm{~m}$, grain wear in the segment for both types of hardness stabilizes. The binder consumption in the A1 segment is $17 \%$ higher than in A2. It should be noted that grain abrasive wear is proportional to the wear of the segment's metallic binder. After passing the friction path above $2000 \mathrm{~m}$, as indicated by the optical analysis and the evaluation of the diamond grains wear in this calculation, the process of stabilizing the consumption of diamond grain volumes for both types of segments was observed.

The assessment of abrasive grains wear was made on the basis of a general and detailed analysis of the surface after each abrasive load cycle at $10 x$ the magnification of the working surface in determining the total amount of working grains. Then, observations were made at 50x magnification in the $1 \times 1 \mathrm{~mm}$ field of observation, on the basis of which the total volume loss was estimated related to the total number of protruding grains, on the area under assessment after each cycle. To determine the micro-grain consumption, the method $(0 \div 1)$ was used to calculate the volume loss in percentage terms, which included: micro chippings at grain edges, occurrence of cracks and grains lost from the segment matrix. Figure 2 presents the image of the wear of diamond grains formed in a synthetic binder made for a segment made of polyurethane resin filled with quartz powder.
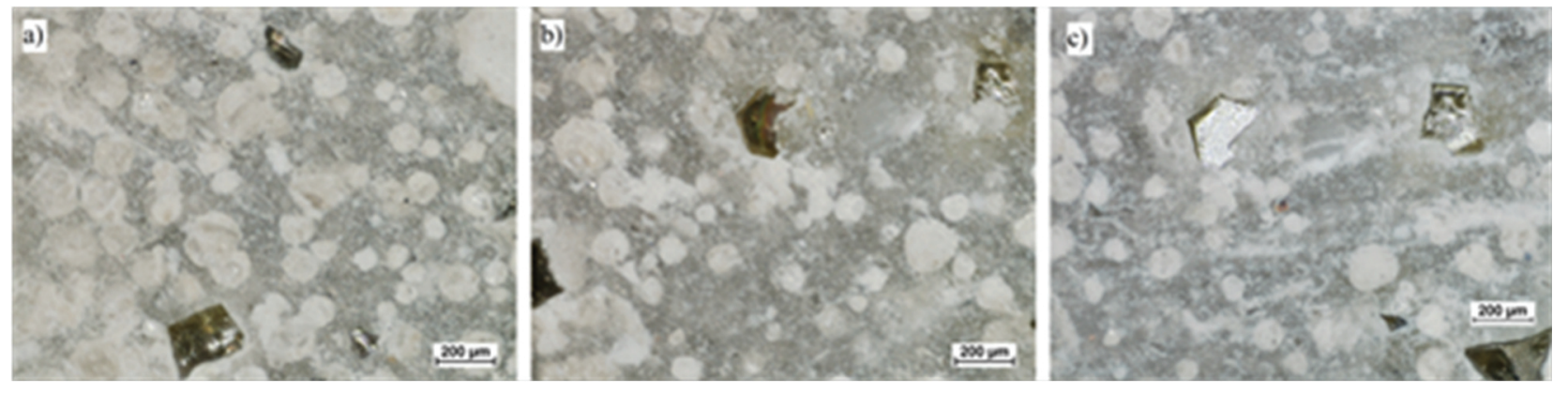

Figure 2 Representative photographs of microscopic analysis of diamond segments formed on the basis of polyurethane resin

Segment analysis on a synthetic binder showed a minimum loss of adhesive mass determined for 6 cycles of abrasive impact, where in Figure 2a, after 2 interaction cycle stable grain seating with the minimum amount of chipping on sharp edges, Figure $\mathbf{2 b}$, after the 4th interaction cycle the image shows a stable degree Grain seating in the binder, Figure 2c, after 5 cycles of work, despite the occurrence of the surface mesh of cracks on the surface of the grain, they are firmly embedded in the binder. It was observed that the background of the binder shows a uniform distribution of the filler in the form of quartz powder, which results from the good homogenization of the binder components before forming.

\section{CONCLUSIONS}

The analysis of the mass loss of the binder in the segment work process on the metallic bond showed a lower abrasive wear for the A2 type segments by $17 \%$ compared to the A1 type segments, the relation between hardness and abrasive wear showed direct proportional relations.

The tribological tests of segments formed on synthetic polyurethane resins modified with mineral filling in the form of quartz flour, which allowed to obtain the hardness of the $60 \mathrm{ShD}$ segment, showed a smaller loss of mass from the diamond segments than on the metallic bond. 
Analysis of the image from the segments' surface on synthetic binders allows to estimate that the consumption of diamond grains after each test cycle showed a slight degree of their loss in the process of abrasive impact, which allows to state that the degree of maintenance of diamond grains in the synthetic binder used to process the granite surface is satisfactory.

\section{REFERENCES}

[1] RAJCZYK, J. and KOSIŃ, M. Technological processes in natural stone processing with recommendations of processing tools evaluation. Advanced Materials Research. 2014. vol. 1020, pp. 60-65.

[2] RAJCZYK, J. and KOSIŃ, M. Methodology of analyzing a new geometry design of a friction plate effect on the engineered surfaces. In IET conference publications, 2011. pp. 2-177 - 2-180.

[3] KNAPIŃSKI, M. and RAJCZYK, P. Innovative Methods for Modeling Diamond Tools for Surface Grinding of Stone, Innovation in Management and Production Engineering. T.1 (red.) Knosala Ryszard. Opole: Publishing house of the Polish society for production management (PTZP). 2018, pp. 564-574.

[4] RAJCZYK, M. and RAJCZYK, P. Elements of diamond tools development used in the technology of building materials processing. IOP conference series: materials science and engineering. 2019. vol. 471, pp. 1-6.

[5] JAWORSKA, L. Diamond, preparation and use in machining. WNT. Warsaw. 2017.

[6] RAJCZYK, J. Scientific Basics of Selection of Geometric Structure and Disc Kinematics of Working Tools of Concrete Surface Machining Machines. Czestochowa University of Technology Publishing. Series of monographs 98. Czestochowa. 2004.

[7] JANKOWSKI, E. and SKUPIŃSKI, S. Abrasive Materials and Products. WNT, Warszawa. 1971.

[8] STANIEWICZ-BRUDNIK, B. Grinding wheels made of regular boron nitride with a ceramic binder. Mechanic. 2010. no. 8-9, pp. 31-34.

[9] 3m technical information materials (USA). 2017.

[10] Information and technical materials of KGS Diamond International (Netherlands). 2019.

[11] Information and technical materials of the company Huang Chang Diamond Stone Tools (China). 2018.

[12] RAJCZYK, P. and KNAPIŃSKI, M. Theoretical-Experimental Analysis of the Production Process of Grinding Wheels Intended for Finishing Grinding of Granite Surfaces. Management engineering. Digitization of production. Research news 1 (ed.) KNOSALA Ryszard. PWE. Warsaw. 2019. pp. 595-611.

[13] KACALAK, W., TANDECKA, K. and LIPIŃSKI, D. Methods for identifying changes in the active state of grinding wheel surfaces as a result of grinding, sticking or chipping of grains. Mechanic. 2014. no. 9.

[14] Information materials from Huntsman Polyurethanes (Poland). 2019.

[15] BAKOŃ, A. and BARYLSKI, A. Grains and Diamond Microns. Gdansk University of Technology Publisher, Gdańsk, 2017.

[16] KUSHCHENKO, A.V. and BASHKAREV A.Y. Increasing durability of connections with a tightness polymer coating. Engineering Bulletin. 2015. no. 10, pp. 60-64.

[17] PETROV, V.A., BASHKAREV A.Y. and VETTEGREN V.I. Physical Basis of Forecasting the Durability of Structural Materials. 1993. pp. 475.

[18] VETTEGREN, V.I., PONOMAREV, A.V., SOBOLEV, G.A., KULIK, V.B., MAMALIMOV, R.I., SHCHERBAKOV, I.P. and BASHKAREV, A.Y. Changes in the surface structure of the heterogeneous body (diorite) under friction. Fizika Tverdogo Tela. 2018. vol. 60, no. 1, pp. 127-131.

[19] KONOVALOV, V.A. and SHATOKHIN, V.V. The Relationship of the Strength of the Fixing of Grains in Conjunction with the Resistance of a Diamond-Abrasive Tool. VIP. Ukraine. 2009. no. 12, pp. 508-513. 